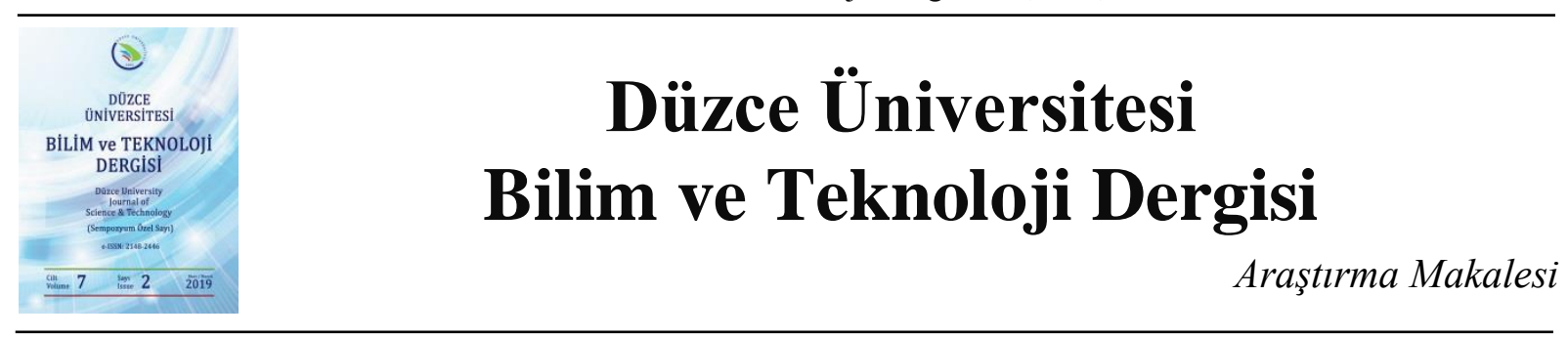

\title{
Polyamid Malzemelerde Yüzey Pürüzlüğünün Belirlenmesi İçin Yapay Zeka Destekli Bir Uygulama Tasarımı
}

\author{
Mustafa BOZDEMIR $^{\text {a,* }}$ \\ ${ }^{a}$ Makine ve Metal Teknolojileri Bölümü, Kırıkkale Meslek Yüksekokulu, Kırıkkale Üniversitesi, Kırıkkale, \\ TÜRKIYYE \\ * Sorumlu yazartn e-posta adresi: mustafabozdemir@kku.edu.tr
}

\begin{abstract}
ÖZET
Mühendislik işlemlerinde, yüzey kalitesi malzemelerin kalite göstergelerinden birisidir. Talaşlı imalat işlemlerinde elde edilmek istenen yüzey kalitesi, yüzey pürüzlülüğü ölçümüyle kontrol edilir. Yüzey pürüzlülüğü oluşumunu etkileyen birçok faktör bulunmaktadır. Kullanılan kesici takım cinsi, malzeme türü, kesme şartları gibi faktörler yüzey pürüzlüğü değişimini etkiler. Bu çalışmada, deneysel olarak bulunan polyamid malzeme ortalama yüzey pürüzlüğü değerleri geliştirilen uzman sistem bilgi tabanına dinamik olarak yüklenmektedir. Genel talaşlı imalat kesme şartlarına ait bilgilerde sisteme karar verme aşamasında destek olmaktadır. Bu sayede, polyamide malzemeler için belirlenen kesme durumlarında oluşması beklenen ortalama yüzey pürüzlüğü değeri, uzman sistemin sağladığı avantajla çok hızlı ve doğru şekilde belirlenebilmektedir.
\end{abstract}

Anahtar Kelimeler: Uzman sistem, Yüzey pürüzlülüğ̈̈, Kesme şartları

\section{The Application Design Of Artificial Intelligent Assisted For The Detection Of Surface Roughness In Polyamide Materials}

\begin{abstract}
In the process of engineering the surface quality is one of the indicators of the quality of materials. Surface quality which is aimed to attain in metal cutting processes is controlled by the measurement of surface roughness. There are many factors that affect the formation of surface roughness. Factors such as the type of cutting tool that is used, the type of material, cutting conditions influence the formation of surface roughness. In this study, polyamide materials surface roughness values which are detected experimentally are dynamically loaded on the database of expert system computer program that is developed. Information about general metal cutting conditions is also supportive in the process of detection of system. In this way polyamide material average surface roughness values that is expected to occur in the detected cutting conditions can be estimated fast and correctly with the help of the expert system.
\end{abstract}

Keywords: Expert system, Surface roughness, Cutting conditions 


\section{GiRISS}

$\dot{I}^{\prime \prime m}$ malat işlemlerinde hassas yüzey pürüzlülük değeri elde edebilmek, malzeme kalitesi ve işleme parametrelerine bağlıdır. Talaşlı imalat işlemlerinden sonra oluşan yüzey kalitesi, yüzey pürüzlülüğü ölçümüyle kontrol edilir. Yüzey pürüzlülüğü oluşumunu etkileyen birçok faktör bulunmaktadır. Kullanılan kesici takım cinsi, malzeme türü ve kesme şartları gibi faktörler yüzey pürüzlüğü değişimini etkiler [1,2]. Delik delme, frezeleme ve tornalama gibi talaşlı imalat işlemlerinde iş parçaları üzerinde istenilen yüzey geometrisi ve yüzey hassasiyetini elde etmek amaçlanmaktadır. Teknolojinin gelişmesi ile birlikte modern talaş kaldırma yöntemlerinde boyutsal tamlığa artı olarak yüzey kalitesinin oluşumu ve kontrolü de önem kazanmıştır. Talaş kaldırma yöntemlerinde amaç, parçaya şekil vermenin yanında, geometrik, boyutsal ve yüzey pürüzlüğ̈̈ yönünden, imalat resminde istenilen tolerans sınırları içerisinde imal etmektir [1].

Yüzey pürüzlülüğü; malzemenin özelliklerine ek olarak, takım geometrisi (takım uç yarıçapı, kesici geometrisi, kesici açıları vb.) ayrıca talaşı imalat kesme şartları (kesme hızı, ilerleme hızı, talaş derinliği vs.) gibi işleme parametreleriyle yakından ilgilidir. Daha uzun parça ömrünün sağlanması için, geliştirilmiş kalite veya iş parçası yüzey tamlığı şarttır [1-3]. Yüzey pürüzlülüğü oluşumu, malzemeye ait 1s1 iletimi, sürtünme, yorulma direnci ve yağlama özellikleri gibi ürünün kalitesinin artırılmasında karakteristik özellikleri etkilemektedir. İş parçası yüzey pürüzlülügü̈ değerinin azalması, malzemenin yüzey kalitesinin artması sağlar [4].

Yüzey pürüzlügü araştırmalarında en önemli unsurlardan biride, malzeme türüdür. Makine tasarım ve imalatında kullanılan farklı özellikte pek çok malzeme bulunmaktadır. Bunların içerisinden seçim yaparken ucuz, kolay işlenebilir, hafif, dayanımı yüksek, aşınmaya dirençli ve sessiz çalışabilme gibi özellikler tercih nedenini oluşturmaktadır.

Yapılan bu çalı̧̧mada, endüstriyel plastik malzeme türlerinden birisi olan ve sanayide yaygın kullanım alanı bulunan polyamid türü malzemelerin talaşlı imalat sırasında yüzey pürüzlüğü oluşumu deneysel olarak incelenmiştir. Elde edilen deneysel sonuçlar hızlı ve etkili bir yorumlama yapılmak üzere, geliştirilen bir uzman sistem yapay zeka programıyla desteklenmiştir.

Günümüzde uzay endüstrisinden inşaat sanayisine kadar farklı kullanım alanları bulunmaktadır. Mühendislik plastiklerinin farklı çeşitleri ve özellikleri bulunmaktadır. Polyamidler, en yaygın kullanılan bu plastik türlerinden biridir [5]. Döküm olarak elde edilen ve bazı katkılarla mekanik özellikleri iyileştirilmiş türüne, döküm polyamid ya da diğer endüstriyel özel adıyla Kestamid adı verilmektedir. Polyamidlerin mühendislik plastiği olarak kullanılmaya başlandığı 1960'lardan bu güne birçok farklı özelliklerine dair araştırmalar yapılmıştır. Bu araştırmalardan bazıları polyamid malzemelerin sürtünme durumlarının araştırılmasına yöneliktir [6].

Polyamid malzemeler sanayide kuru ve içerisine çeşitli katkı malzemeleri katılarak kullanılabilmektedir. İçerisinde herhangi bir katkı bulunmayan polyamid türlerinin sürtünme kuvveti diğer metallere göre düşüktür. Sürtünme kuvvetlerinin azaltılması amaciyla polyamid malzemelerin içerisine farklı yağlayıcıların katıldığı çalışmalar da bulunmaktadır [7-10]. Polyamid malzemelerin içerisine yağ eklenebilme özelliği sayesinde, özellikle sürtünmeli yataklar, miller, kızaklar ve kamlar gibi makine elemanlarının çalışma ömrü uzamaktadır. 
Polyamid malzemeler talaşlı imalat yöntemleri kullanılarak işlenirler. Farklı polyamid türlerinin talaşlı imalat yöntemleriyle işlenebilirliği, kesme kuvvetleri ve yüzey pürüzlülüğünün incelenmesi son dönemlerde güncel bir araştırma alanı olmuştur. Kesici türleri, kesme hızı, talaş derinliği, kullanılan malzeme niteliği vb., gibi bir çok parametre kesme kuvvetleri ve yüzey kalitesi üzerine etkili olmaktadır [5,11]. Polyamid malzemelerin yüzey pürüzlügüunün hava ortam içerisindeki nemden ve çevresel faktörlere bağlı sudan etkilendiği yapılan deneysel çalışmalarda ispatlanmıştır. Bu nedenle bu tip plastik malzemelerin çalışma ortamlarının çok iyi biliniyor olması gereklidir [12,13].

Bu çalışmada Polyamid (PA6G) 'nin sanayide yaygın olarak bilinen ismiyle Kestamid malzemenin talaşlı imalatta yüzey pürüzlüğü araştırılmıştır. Deneyler sonrasında elde edilen sonuçların kullanıcılar tarafından kolaylıkla kullanılmasını sağlamak amacıyla bir yapay zeka programı geliştirilmiştir. Yapay zeka programının içeriğini uzman sistem programla yöntemi oluşturmaktadır. Elde edilen deneysel sonuçlar uzman sistem yapısı içerisinde programa girilerek, hızlı ve doğru sonuç veren bir program geliştirilmiştir.

\section{Polyamid MaLzemEnin İșLENMESi}

Çalışmaya öncelikle deneysel verilerin elde edilmesiyle başlanmıştır. Polyamid malzemenin işlenmesinde Taksan TMC 700V CNC dik işlem tezgahı kullanılmıştır. Dik işlem tezgahı için talaşlı imalat kesme parametreleri kontrollü değiştirilerek ortalama yüzey pürüzlülük oluşumu deneysel olarak incelenmiştir. Dik işlem tezgahının kesme hızı (Vc), ilerleme hızı (f) ve kesme derinliği (ap) değiştirilerek belirlenen farklı türlerdeki polyamid malzemeler üzerinde deneyler yapılmıştır.

Deneylerde kullanılan Polyamid malzeme $46 \mathrm{~mm}$ kalınlıkta plaka halinde POLIMERSAN firmasından temin edilmiştir. Polyamid malzeme firma ürün katalogunda POLIKES (PA6G) olarak tanımlanmıştır. Levha halinde alınan PA6G 112x82x46 mm boyutlarında kesilerek deneylere hazır hale getirilmiştir. Deneyde kullanılan PA6G malzemeye ait fiziksel özellikler Tablo 1' de gösterilmiştir.

Tablo 1. PA6G malzemeye ait mühendislik değerleri

\begin{tabular}{lcc}
\hline Özellik & Birim & Değer \\
\hline Özgül ağılık & $\left(\mathrm{g} / \mathrm{cm}^{3}\right)$ & 1,15 \\
\hline Servis sıcaklı̆̆ & $\left({ }^{\circ} \mathrm{C}\right)$ & 100 \\
\hline Ergime noktası & $\left({ }^{\circ} \mathrm{C}\right)$ & 190 \\
\hline Termal uzama & $\left(1 / \mathrm{K}^{*} 105\right)$ & 8 \\
\hline Çekme dayanımı & $\left(\mathrm{N} / \mathrm{mm}^{2}\right)$ & 55 \\
\hline Kopma dayanımı & $\left(\mathrm{N} / \mathrm{mm}^{2}\right)$ & 88 \\
\hline Kopma uzaması & $(\%)$ & 10 \\
\hline Elastiklik modülü & $\left(\mathrm{N} / \mathrm{mm}^{2}\right)$ & 3900 \\
\hline Su emme & $(\%)$ & 7 \\
\hline Rockwell & $(\mathrm{skala})$ & $\mathrm{M} 88$ \\
\hline Bilya çentiği 358/30 & $\left(\mathrm{N} / \mathrm{mm}^{2}\right)$ & 110 \\
\hline
\end{tabular}


Deneylerin yapılmasında Taksan marka TMC 700V CNC dik işleme merkezi kullanılmıştır. Tezgah $15 \mathrm{~kW}$ gücünde, metrik ve inch birimlerinde ISO formatında programlanabilen üç eksende lineer ve dairesel enterpolasyon yapabilen bir sisteme sahiptir. Kontrol ünitesi FANUC serisi O-M'dir. Tezgah tablası X,Y,Z yönlerinde otomatik hareket edebilmektedir. Şekil 1' de deneylerin yapılmasında kullanılan Taksan dik işlem merkezi görülmektedir.

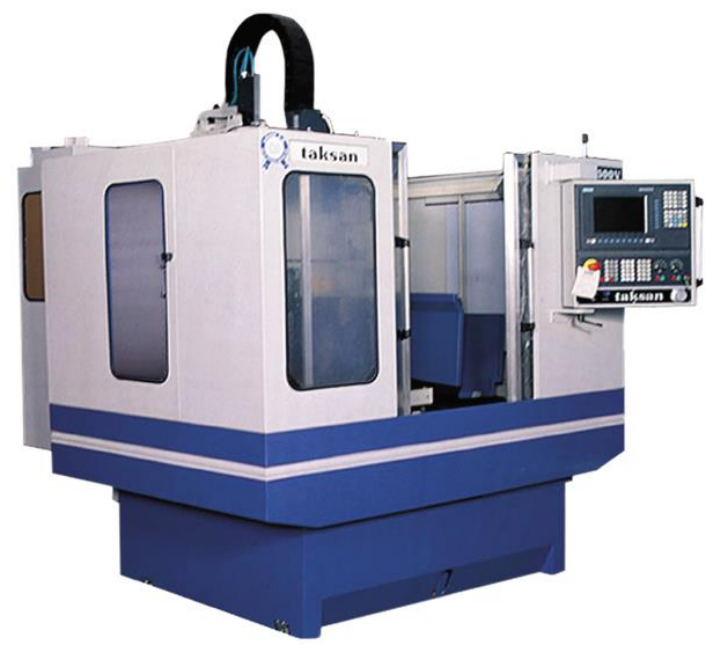

Şekil 1. TAKSAN TMC 700V CNC dik işlem merkezi

Şekil 2'de deneyde kullanılan malzemenin Bilgisayar Destekli Tasarım(CAD) modeli görülmektedir CNC dik işlem tezgahında, kestamid malzemesinin talaş kaldırılarak işlenmesi esnasında, ortalama yüzey pürüzlügündeki değişimler de MarSurf PS1 portatif yüzey pürüzlülük ölçüm cihazı kullanılarak ölçülmüştür. Cihazın ölçüm iğnesi $2 \mu \mathrm{m}$ ölçüm yarıçapında ve baskı kuvveti yaklaşık $0,7 \mathrm{mN}$ 'dır. Pürüzlülük ölçümün tarama uzunluğu 5,6 mm olarak ayarlanmıştır.
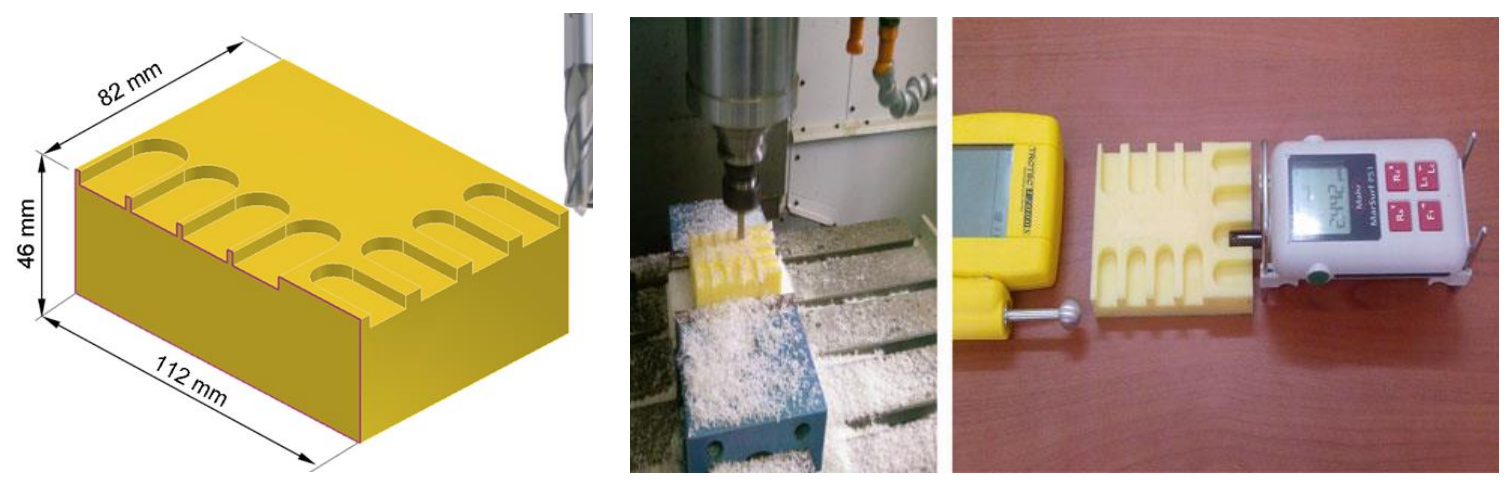

Şekil 2. Deneyde kullanılan malzemenin CAD modeli ve işlenmesi

Kesme işleminde karbür 14 mm çapında parmak freze kesici takım kullanılmıştır. Takım, DIN 81800 standardında üretilmiş, dört kesme kenarına sahip, $30^{\circ}$ helis açısı, WC (Tungsten Carbide) oranı $\% 87,7$, kobalt oranı \%12,3, TRS $4200 \mathrm{MPa}$, sertliği 92,5 HRA (Rockwell sertlik değeri), tane büyüklüğü $0,5 \mu \mathrm{m}$ sahip ve yüksek aşındırma ve etki kabiliyetine sahiptir. Kesici takım ISO serisi DIN 6388E pens başlığ 1 yardımıyla iş miline bağlanmıştır. 
Kesme Parametreleri: Talaşlı imalat yüzey frezeleme işleminde kesme parametreleri, talaş derinliği, ilerleme hızı, kesme hızı, kesici takım tipi ve polyamid malzemeden yararlanılarak ortalama yüzey pürüzlülükleri elde edilmiştir. Tablo 2' de deneylerde kullanılan kesme parametreleri görülmektedir.

Tablo 2. CNC frezeleme için kesme parametreleri

\begin{tabular}{lccc}
\hline \multicolumn{1}{c}{ Kesme şartları } & Birimi & Veriler & Veri sayısı \\
\hline İlerleme hızı, $[f]$ & $m m / d k$ & $100,120,140$ ve 160 & 4 \\
\hline Talaş derinliği, $\left[a_{p}\right]$ & $m m$ & $1 ; 1,5 ; 2 ; 2,5$ ve 3 & 5 \\
\hline Kesme hızı, $\left[V_{c}\right]$ & $m / d k$ & $90 ; 110$ ve 130 & 3 \\
\hline Çap, $[C \zeta]$ & $m m$ & 14 & 1 \\
\hline Takım cinsi, $[T]$ & - & Karbür & 1 \\
\hline Malzeme, $[M]$ & - & Nemli ve Nemsiz & 2 \\
\hline
\end{tabular}

\section{GELISTTIRILEN PROGRAM}

Deneysel olarak elde edilen sonuçların hızlı ve doğru yorumlanması için Visual Basic 6.0 Programı kullanılarak bir uzman sistem programı geliştirilmiştir. Geliştirilen uzman sistem programı deneysel verilerin bilgi tabanına if-then yapıları kullanılarak öğretilmesi sonrasında, doğru ve hızlı karar verme süreciyle etkili sonuç bulma ilkesiyle çalışmaktadır. Program içerisindeki tüm veriler deneysel çalışma esas alınarak oluşturulmuştur. Malzemenin cinsi, kesicinin cinsi, kesme hızı, ilerleme hızı, talaş derinliği vs., gibi daha bir çok faktör ortalama yüzey pürüzlüğü oluşumunu etkilemektedir. Kullanılan malzeme ve kesici özellikleri bilinse bile, kesme parametrelerinin (kesme hızı, ilerleme, vb.) farklı seçilmesi beklenen ortalama yüzey pürüzlülüğü oluşumunu olumsuz etkileyebilir. $\mathrm{Bu}$ yüzden yüzey pürüzlülügü konusunda yapılan çalışmalar çoğunlukla deneysel incelenmektedir. Elde edilen deney sonuçları ise tablolar ya da grafiklerle bilimsel olarak yayınlanır. $\mathrm{Bu}$ sonuçların bilgisayar tarafindan kontrol edilmesi, bazı değerlerden çıkarım yaparak faklı durumlarda tahmin yapması, uzmanlık bilgilerinin yaygınlaştırılması ve insan hatası riskinin en aza indirilmesi amacıyla uzman sistem temelli çalışan bir program hazırlanmıştır.

Bir mühendislik probleminin çözümünde, konunun uzmanı gibi davranan programlardır. Uzman sistem programları veri işlemeye gerek duymadan, bilgi işlemeye geçebilen yapılarda hazırlanırlar. Geleneksel bilgisayar programlarıyla uzman sistem programlarında algoritma ve çıkarım mekanizmaları yer değiştirmiştir Uzman sistem programlarda, bilgi tabanlı problemleri daha geniş bir perspektifte inceleyerek, problemin çözümünde gerçek insan zekâsını taklit etmektedir. Bu nedenle bir yapay zeka uygulama alanı olarak bilinmektedir. Uzman sistem yapıları; özel problemlerinin çözümünde kullanılırken, konu uzmanına ait tecrübe bilgisini ve karar vermeye ait çıkarım işlemini taklit etmeyi amaçlayan programlardır [14-16].

Şekil 3'de Yüzey pürüzlügü belirleme programının yapısı görülmektedir. Uzman sistem programı karar verme mekanizmasının çalışmasında, kullanıcı-bilgisayar iletişimini yönlendiren arayüz sayesinde uygulanacak talaşlı imalat şartlarına ait bilgiler sağlanmaktadır. Gerekli bilgiler çıkarım mekanizması aracılığıyla sağlandıktan sonra, uzman sistem bilgi tabanı ve veri tabanı kayıtlarını 
değerlendirir. Uzman sistem kural bilgi tabanı ve tasarım veri tabanında yüzey pürüzlülük değeri çıkarım mekanizması tarafından belirlenmektedir. Uzman sistem programlarında bulunması gereken üç temel kısım Şekil 2 'de görülmektedir. Bunlar [17]; 1. Uzman sistem bilgi tabanı, 2. Sonuç çıkarım mekanizmas1, 3. Uzman sistem ara yüzüdür.

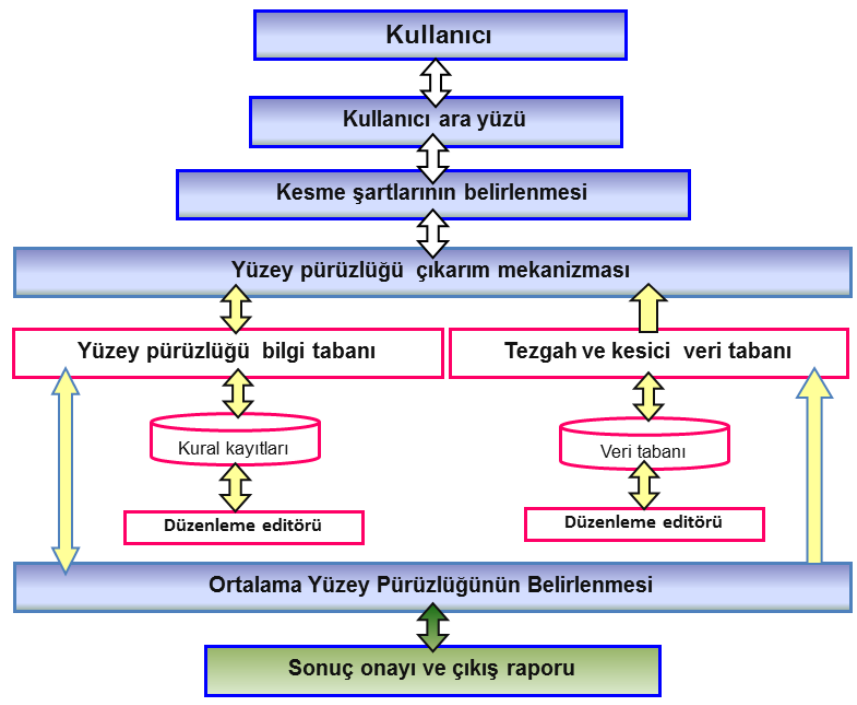

Şekil 3. Geliştirilen uzman sistem programının yapısı

Uzman sistem bilgi tabanı, uzmanlardan, yayınlanmış veya yayınlanmamış kaynaklardan, kitaplardan ve diğer literatürden elde edilen bilginin bulunduğu, saklandığ 1 ve kullanılması gerektiğinde kolaylıkla erişilebilen bir yapıdır. Uzman sistemin çıkarım mekanizması, bilgi tabanındaki kuralları, gerçekleri ve diğer tüm bilgileri kullanarak hem ileriye hem de geriye doğru zincirleme metodu ile sonuca varabilen mekanizma yapısıdır. Programa ait kullanıcı ara yüzü, uzman sistemi kullanan önemli bir bileşendir [17].

Yüzey pürüzlülük değerinin bilgisayar destekli bulunması amacıyla hazırlanan programının karar verme yapısında uzman sistem programlama mantığı kullanılmıştır. Tablo 3' de yüzey pürüzlülük durumlarının kontrolünde kullanılan basit bir dizi kural örneği görülmektedir.

Tablo 3. Örnek bir If-then kural yaplst

Kural 1

If kesicitürü $=\mathrm{HSS}$ and kesicicapi $=10 \mathrm{~mm}$ and $\mathrm{Kesmehizi}=100 \mathrm{~m} / \mathrm{dk}$ and ilerlemehizi $=120 \mathrm{~mm} / \mathrm{dk}$ and Talasderinligi $=1 \mathrm{~mm}$ Then $\mathrm{Ra}=2,345$

Geliştirilen uzman sistem programının içerisinde 120 tane özel tanımlanmış kural kaydı vardır. Uzman sistem programının, bilgi tabanı kural kaydını hatasız yapabilmesi amacıyla, kullanıcıya kural ekleme yetki kontrolü sınırlandırması yapılmıştır. Yetkisiz personele bu işlem kapatılabilmektedir. Karar aşamasında çıkarım mekanizması bilgi tabanından aldığı bu kural cümlelerini kullanmaktadır. Tasarım bilgi kurallarının düzenlenmesi ve görüntülenmesini sağlamak amacıyla, uzman sistem programı içerisinde kuralların oluşturulması, düzenlenmesi ve mevcut kural kayıtlarını görüntüleme sistemi eklenerek, kullanıcı işlemleri kolaylaştırılmıştır. 
Visual Basic programı kullanılarak hazırlanana ara yüzler, kullanıcıya yardımcı olmak ve hızlı bir şekilde sonuca ulaştıracak özellikte tasarlanmıştır. Şekil 4'de bu programa ait ortala yüzey pürüzlüğünün belirlendiği ara yüz görülmektedir.

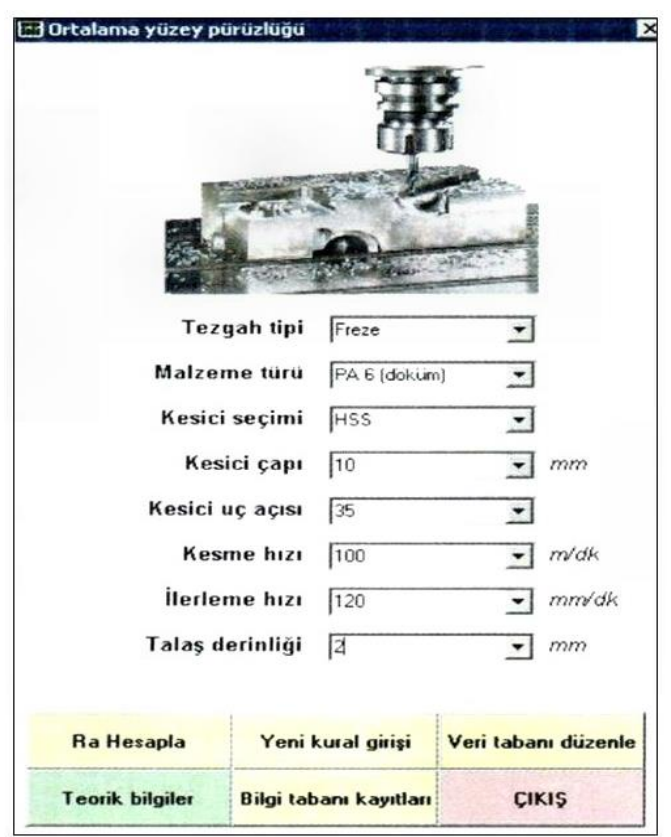

Şekil 4. Program ana menüsü

Programın çalışmasının temelini oluşturan bilgi yapısı, daha önceden yapılan farklı malzeme ve kesme şartlarına ait elde edilen deneysel bilgilerin, uzman sistem bilgi tabanı için kural kaydı bilgilerine dönüştürülerek saklanmasına dayalıdır. Deneysel bilgilerin hatasız ve kolay yazılabilmesi amacıyla Şekil 5'te görülen "Otomatik kural oluşturma" menüsü hazırlanmıştır.

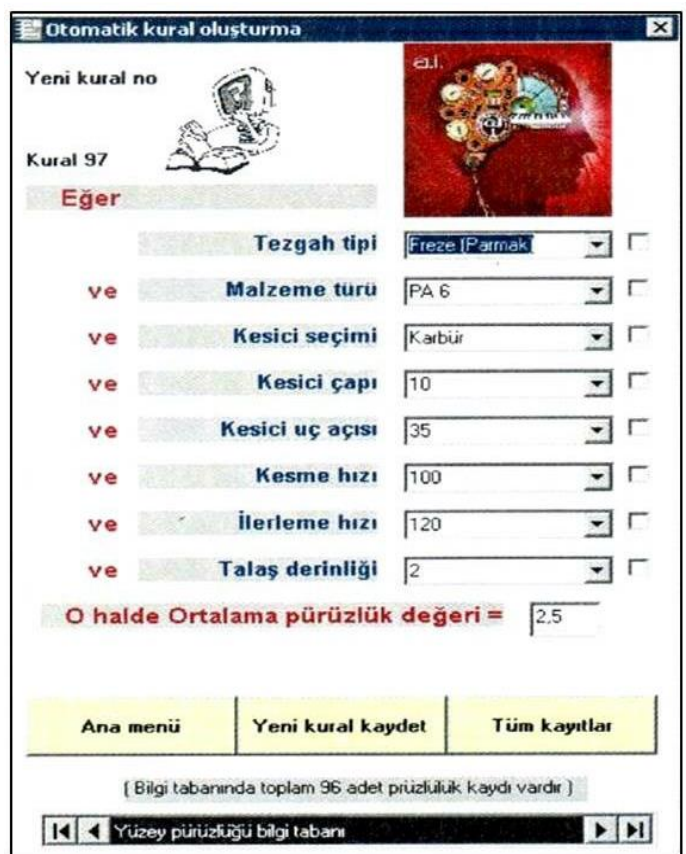

Şekil 5. Yeni kural eklemek için otomatik kural oluşturma menüsü 
Her bir deney durumuna ait şartlardan ilgili durumlar önce sağ yan taraftaki kontrol kutusunda işaretlenir ve olması gereken değeri kutucuklardan seçilmelidir. Tüm deney şartları belirlendikten sonra ölçülen ortalama yüzey pürüzlülük değeri belirlenir. Bu işlem yapılan tüm deneysel çalışmalar için sürekli tekrar edilmelidir. Uzman sistem bilgi tabanında ne kadar fazla bilgi kaydı yapılırsa, sonuç için cevap verme doğruluk derecesi yükselecektir.

Bilgi tabanı dosyası, uzmanlık bilgilerini içerdiği için, uzman sistemin en önemli veri yapısı kaydını oluşturmaktadır. Gelişmiş uzman sistem bilgi tabanı dosyaları, ticari amaçlı satılabilir ya da kopyalanıp çoğaltılabilir. Uzman sistem otomatik kural oluşturma menüsünden gerektiğinde, tüm kural kayıtlarına erişim sağlanabilmektedir. Uzman kayıt görüntüleme işleminde tasarım bilgi tabanına eklenen kural kayıtlarına ait detaylar, mevcut yüklenmiş kural sayısı, sisteme yüklenmiş olan kural dosyasının adı, dosyanın konumu ve tarih-saat gibi tüm bilgililere ulaşılabilir.

Şekil 6'da uzman sistem destekli karar verme yapısına sahip bir çıkarım mekanizmasının ihtiyaç duyabileceği kesici takım bilgilerini içeren veri tabanı yapısı görülmektedir. Bu veri tabanı içerisinde kesicilere ait katalog bilgileri kaydedilmiştir. Bu sayede sisteme kural ekleme aşamasında, hangi tip takım ve çapta kesici kullanılacağı kolaylıkla bu veri tabanından seçilebilir.

Şekil 5 ve 6 ' daki veri tabanı bilgileri uzman sistemin çalışmasında önemli bilgileri içerir. Bu yüzden programın veri tabanı ve bilgi tabanı bölümüne kullanıcı giriş yetki kontrolü sağlanmalıdır. Uzman sisteme kural ekleme yetkisi verilmiş personel tarafından, kuralların eklenmesi, düzenlenmesi ve gerektiğinde görüntülemesini sağlayabileceği ara yüze ulaşım sağlanabilmektedir. $\mathrm{Bu}$ ara yüz üzerindeki kural kaydetme butonuyla yeni kuralların tanımlanması da sağlanabilmektedir.

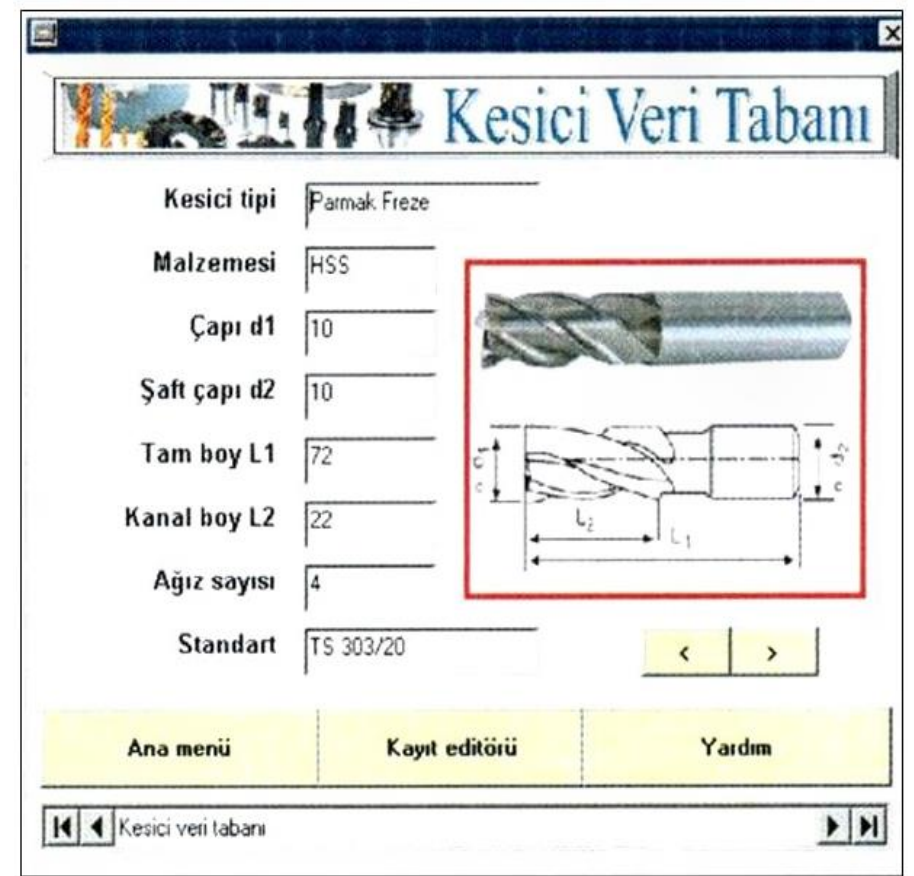

Şekil 6. Kesici veri tabanı kontrol ekranı 
Uzman sistem bilgi tabanı içerisinde yapılacak ekleme işlemlerinde, kullanıcıya bilgilendirme amacıyla ekran uyarı mesajları gönderilmektedir. Bilgi tabanı düzenleme programı kullanılarak bilgi tabanı içerikleri görüntülenebilir ve düzenleme sonrası yenilikler kaydedilebilir

\section{SONUC}

$\mathrm{Bu}$ çalışmada, sanayide yaygın olarak kullanılan polyamid malzemelerin $\mathrm{CNC}$ dik işlem tezgahında işlenirken, talaşlı imalat parametrelerinin ortalama yüzey pürüzlülüğü üzerine etkileri deneysel incelenmiştir. Daha sonrasında deneysel çalışmanın sonuçlarının, uzman sistem temelli bir programla kontrolüne ait bilgi akış ve yönetim biçimleri tanımlanmıştır. Visual Basic ortamında geliştirilen uzman sistem destekli program sayesinde, yüzey pürüzlülügü belirleme, bilgi tabanı kural kaydı oluşturma ve kesici takım veri tabanı hazırlama aşamaları gösterilmiştir. Kullanılan bilgi tabanının kurallarının oluşturulmasında, polyamid malzemenin talaşlı imalat aşamasında CNC dik işlem tezgahında elde edilen gerçek veriler kullanılmıştır. Kesici tipi, kesici çapı, kesme hızı, ilerleme hızı ve talaş derinliği gibi değerler polyamid malzeme için belirlenmiş parametrelerde yüzey pürüzlügü ölçülerek, sonuçlar yapay zeka programına ait bilgi tabanına kural olarak kaydedilmiş̧ir. Bu kayıt bilgileri uzman sistem programına ait çıkarım mekanizması tarafından değerlendirilmektedir. Yapılan bu çalışmayla elde edilen sonuçlar kısaca şu şekilde özetlenebilir;

- Polyamid malzemelerin talaşlı imalat yöntemleriyle işlenmesi sırasında oluşan yüzey pürüzlük değerlerinin araştırılmasına yönelik deneysel bir çalışma yapılmıştır. Bu çalışma sonrasında farklı kesme hızı, ilerleme ve talaş derinliği gibi işleme parametrelerinde oluşan ortalama yüzey pürüzlüğü değerleri elde edilmiştir.

- Kesme parametrelerine göre en iyi ve en kötü yüzey pürüzlülük oluşum kombinasyonları deneylerle ispatlanmış halde, bilgisayar programına öğretilebilmektedir.

- Polyamid malzemenin işlenmesi sonrasında elde edilen deney sonuçlarını kullanan ve bunları işleyerek yorumlayabilen bir yapay zeka programı geliştirilmiştir. Bu program Visual Basic alt yapısını kullanarak uzman sistem yapısıyla tasarlanmıştır. Programla kullanıcı yüzey kalitesi oluşumuyla ilgili ciddi zaman tasarrufu sağlamaktadır.

- Polyamid malzemeye ait ortalama pürüzlük deneysel verileri, programa ait bilgi tabanı dosyası içerisine, geliştirilebilir, çoğaltılabilir, dağıtılabilir ve ticari amaçlı satılabilir bir yapıda kaydedilebilmektedir.

- Geliştirilen uzman sistem program kullanılarak, operatörler için tezgah ön ayarlamaları için gerekli zamanı azaltmaktadır. İstenilen yüzey pürüzlük durumuna göre olması gereken tezgah ayarları listelenebilmektedir.

- Yapay zeka programı içerisinde, insan kaynaklı olabilecek yanlış algılama ve hatalardan arındırılmış bir karar verme yapısı oluşturulmuştur.

TEȘEKKÜR: $\mathrm{Bu}$ çalışma TÜBITAK tarafindan desteklenen, 109M031 numaralı "Kestamid malzemelerde nem faktörünün yüzey pürüzlülüğüne etkisinin incelenmesi” adlı projenin deneysel verileri kullanılarak hazırlanmıştır.

\section{KAYNAKLAR}


[1] T. Özel ve Y. Karpat, "Predictive Modeling Of Surface Roughness And Tool Wear In Hard Turning Using Regression And Neural Networks", International Journal of Machine Tools \& Manufacture, vol.45, pp. 467-479, 2005.

[2] H. K. Tonshoff, C. Arendt, and A.R. Ben, "Cutting Of Hardened Steel", An.of CIRP, vol.49, no.2, pp 547-566, 2000.

[3] A. Acır, "Talaş kaldırma işlemlerinde yüzey pürüzlülüğüne etki eden faktörlerin incelenmesi", II. Makine Tasarım ve imalat Kongresi, Konya, Türkiye, 2003, ss. 209-216.

[4] M. Y. Wang and H. Y. Chang, "Experimental Study Of Surface Roughness In Slot End Milling", International Journal of Machine Tools \& Manufacture, vol. 44, pp. 51-57, 2004.

[5] J. P. Davim, L. R. Silva, A. Festas and A. M. Abrao, "Machinability Study On Precision Turning Of PA66 Polyamide With And Without Glass Fiber Reinforcing", Materials and Design, vol.30, pp.228-234, 2009.

[6] N. Adams, "Friction And Deformation Of Nylons", Journal of Applied Polymer Science, vol.7, pp. 2075-2103, 1963.

[7] P. Samyna, P. Baets, G. Schoukens, and I. Van Driessche, "Friction, Wear And Transfer Of Pure And Internally Lubricated Cast Polyamides at Various Testing Scales", Wear, vol. 262, pp.14331449, 2007.

[8] M. Palabiyik and S. Bahadur, 'Mechanical And Tribological Properties Of Polyamide 6 And High Density Polyethylene Polyblends With And Without Compatibilizer,' Wear, vol. 246, pp.149$158,2000$.

[9] P. Samyn and T. M. Tuzolana, "Effect Of Test Scale On The Friction Properties Of Pure And Internal-Lubricated East Polyamides At Running-In", Polymer Testing, vol. 26, pp.660-675, 2007.

[10] CZ Liu, J.Q. Wu, J.Q. Li, L.Q. Ren, J. Tong and R.O. Arneli, "Tribological Behaviors Of PA/UHMWPE Blend Under Dry And Lubricated Condition", Wear, vol. 260, pp.109-115, 2006.

[11] F. Mata, P. Reis and J.P. Oavim, "Physical Cutting Model Of Polyamide Composites (PA66 GF30)", Materials Science Forum, vol. 514, pp. 643-647, 2006.

[12] M. Bozdemir, "The Effects Of Humidity On Cast PA6G During Turning And Milling Machining", Advances in Materials Science and Engineering, 2017.

[13] M. Bozdemir, "Prediction Of Surface Roughness Considering Cutting Parameters And Humidity Condition İn End Milling Of Polyamide Materials", Computational Intelligence and Neuroscience, 2018.

[14] N. Allahverdi, Uzman Sistemler, İstanbul, Türkiye: Atlas Yayınları, 2002, ss 1-60.

[15] O. Poyrazoğlu, M. Gülesin ve Y. Kayır, "Uzman sistem tekniklerine dayalı alışılmamış imalat yöntemlerinin tespiti”, Makine Tasarım ve İmalat Yön. Konferans1, Ankara, Türkiye, 1997, ss.80-89. 
[16] E. Turban, Decision support and expert systems, N.York, USA: Macmillan Publushing Company, 1990, ss 20-60.

[17] M. Bozdemir and F. Mendi, "The Knowledge Management System Architecture For Artificial Intelligent Aided Systematic Design", Journal of The Faculty of Engineering and Architecture of Gazi University, vol. 20, no. 2, pp.267-274, 2005. 